1. Central Park Medical College Lahore.

2. Central Park Medical College Lahore.

3. Central Park Medical College Lahore.

Correspondence Address: Dr. Hijab Batool

Central Park Medical College Lahore.

Batool.hijab@gmail.com

Article received on:

02/06/2016

Accepted for publication:

14/11/2016

Received after proof reading: 18/01/2017

\title{
INTERACTIVE SESSIONS; \\ LECTURES AND SMALL GROUP DISCUSSIONS: A COMPARATIVE STUDY IN SUBJECT OF PATHOLOGY AMONG UNDERGRADUATE STUDENTS OF CENTRAL PARK MEDICAL COLLEGE.
}

\section{Dr. Hijab Batool ${ }^{1}$, Asim Mumtaz ${ }^{2}$, A.S Chughtai ${ }^{3}$}

\section{Statement of novelty:}

Impact of small group discussions on students' learning abilities.

\begin{abstract}
Objectives: To compare the perception of students about two different teaching methods in the subject of pathology at Central Park Medical College Lahore. Background: In medical education, it becomes essential to adopt an approach of teaching and learning that is best suited to the undergraduate medical students. Many studies have revealed that small group discussions lead to an improved and active learning as compared to conventional didactic lectures. Hence, new research is required to identify the preferences and needs of the medical students in relation to their daily learning activities. Study Design: Cross sectional study. Setting: Central Park Medical Lahore. Materials and methods: Comparative analysis of lectures and SGD was done via a feedback performa which was distributed among third $(n=105)$ and fourth year $(n=114)$ MBBS students during a small group discussion session. The students were explained about the purpose of study and 20 minutes were given to fill the performa. Feedback performa comprised of selecting the preferred method of teaching in subject of Pathology at Central Park Medical Lahore. Results: The study revealed that students were satisfied with the current teaching pattern in pathology. $68.9 \%$ of the participants preferred SGDs over lectures as the ideal teaching modality in Pathology. According to $47.9 \%$ of the students the appropriate time for a single lecture of Pathology should be 30 minutes. $55.2 \%$ of the participants suggested discussion as the most helpful method of teaching during an SGD. Conclusion: The findings of this study revealed that students preferred SGD as the most helpful method of learning in subject of pathology. SGD of the topics which had been covered in the comprehensive lectures in the same week lead to a better understanding of the topic resulting in an improved and active learning of the students.
\end{abstract}

Key words: $\quad$ Lectures; Small Group Discussion; Teaching Methods; Medical Education

Article Citation: Batool H, Mumtaz A, Chughtai AS. Interactive sessions; lectures and small group discussions: a comparative study in subject of pathology among undergraduate students of central park medical college. Professional Med J 2017;24(1):195-199. DOI: 10.17957/TPMJ/17.3475

\section{INTRODUCTION}

Choosing an effective teaching methodology is a very important step in educational design. The most conventionally used educational technique in institutes is through didactic lectures or large class format (LCF). In contrast to this primitive technique, participation and involvement of students in small group discussions(SGD) often leads to improved, more effective and active learning. In several studies it has been shown that the lecturing methodology has a limited role in transferring conceptual knowledge to students in a uniform and more effective manner. ${ }^{1}$ In this era of medical education, a combination of teaching methodologies can be used among different students with different learning capabilities. ${ }^{2}$ Medical universities should adopt an improved teaching and learning approach that is best suited to the undergraduate medical students. ${ }^{3}$

Delivering lecture is by far the most traditional and frequently used method to impart knowledge to the students despite all the problems that are often attributed to it. ${ }^{4}$ LCF is a convenient method to instruct large groups and can help to direct a demonstration. Lecture is suitable to introduce a subject by providing basic information and necessary background about it. Despite all 
these advantages, LCF does not allow verbal participation, enhance group thinking or speech and motor skills of the students. On the other hand small group discussions are student centered, motivating and help the instructor to realize the potential of his or her students. ${ }^{4}$

The concept of small group discussions may be regarded as a revolution in medical education, however it is not new and can be traced back to Socrates. ${ }^{4}$ Small group discussions help to generate free communication between the faculty members (who act as group leaders) and the participating students. ${ }^{5}$ In contrast to LCF, small group discussions help to reduce the size of the class thus providing the students with more individual attention and helping the teachers to manage the students in a disciplined way. ${ }^{4}$

Small group discussion provides an environment to achieve high standards and objectives in medical education. ${ }^{6}$ Botelho and Donnell reported that small group discussions create an active learning environment for those students with varying levels of mental abilities and intelligence. ${ }^{7}$ Many studies have shown that use of small group discussions facilitates student's learning capabilities. ${ }^{8}$ In a study conducted in India it was reported that the students who were involved in SGDs performed better than those who attended the lectures proving the fact that students perceive the topic in a better way during small group discussions. ${ }^{9}$

Pathology being the backbone of medicine is taught in third and fourth years as per UHS curriculum. By having proper conceptual knowledge of the pathological process of the disease, students can have a better interpretation and command for diagnosis of disease.

Till now not enough studies have been conducted to find out student preferences about different learning methodologies and their perception about Small Group Discussions in subject of Pathology. The effectiveness of any teaching tool can only be acquired by student's feedback. ${ }^{10}$ The objective of this study was to compare perceptions of students about two different teaching methods (LCF \& SGD) in the subject of pathology at Central Park Medical College Lahore (CPMC).

\section{MATERIAL \& METHODS}

It was a cross-sectional study conducted on $3^{\text {rd }}$ and $4^{\text {th }}$ year MBBS students at Central Park Medical College Lahore. A total of 219 undergraduate medical students of third $(n=105)$ and fourth year $(n=114)$ were given the feedback performa. 112 of the participants were female and 107 were male.

Pathology is being taught at Central Park Medical College in a modular pattern which comprises of lectures followed by SGD of the same topics, which have already been covered in the large class format (LCF) in the same week. In LCF whole class (105 students) get a broader overview of the topic whereas in SGD only 10 to 12 students interact with teacher to get a more conducive learning environment and precise knowledge of the topic through clinical scenarios and discussion.

A group of 10-12 students is allocated to each demonstrator for small group discussions. Each clinical case scenario of SGD was prepared according to the syllabus content of University of Health sciences. The course objectives were displayed on notice board two to three days before SGD date. The format of SGD was kept uniform for all groups by providing same teaching material to all teachers conducting SGD. In SGD a case scenario is first introduced to them and students are given 10-15 minutes to discuss its pathological basis with their peers. The teachers engage the students in a learner centered environment and encourage active participation to reach the final conclusion.

Comparative analysis of lectures and SGD was done via a feedback Performa which was distributed among third and fourth year MBBS students during a small group discussion session. The Performa specifically comprised of the questions regarding the lectures and SGD in the subject of pathology and statements about 
satisfaction with the current pattern of teaching in pathology. The students were explained the purpose and aim of this study. An informed consent was sought after a re-assurance that the individual data gathered will remain confidential and will not be shared with any administrative authority. The participants were given 20 minutes to fill the questionnaire after an SGD session.

\section{RESULTS}

The data was gathered and analyzed using percentages of the responses to compare lectures and SGDs in terms of student's preferences

\begin{tabular}{|l|c|}
\hline \multicolumn{1}{|c|}{ Statement } & Responses \\
\hline Satisfied & $70.3 \%(n=154)$ \\
\hline Not satisfied & $29.7 \%(n=65)$ \\
\hline $\begin{array}{c}\text { Table-I. Responses of students on satisfaction with } \\
\text { the current pattern of teaching in the subject of } \\
\text { pathology }\end{array}$ \\
\hline \multicolumn{2}{|c|}{} \\
\hline
\end{tabular}

\begin{tabular}{|c|c|c|}
\hline Objective & Lectures & SGD \\
\hline $\begin{array}{l}\text { Preferred method of } \\
\text { delivering knowledge }\end{array}$ & $31.1 \%(n=68)$ & $68.9 \%(n=151)$ \\
\hline
\end{tabular}

Table-II. Responses of students on preference of teaching methodology in pathology

\begin{tabular}{|l|c|}
\hline \multicolumn{1}{|c|}{ Preferred Methods } & Responses \\
\hline Slide presentation & $6.4 \%(n=14)$ \\
\hline Discussions & $55.2 \%(n=121)$ \\
\hline Open book teaching & $38.4 \%(n=84)$ \\
\hline
\end{tabular}

Table-III. Responses of students on selecting most helpful method of teaching in SGD

\begin{tabular}{|c|c|}
\hline Objective & Responses (\%) \\
\hline $\begin{array}{c}\text { Lecture duration should be of } 30 \\
\text { minutes }\end{array}$ & $47.9 \%(n=105)$ \\
\hline $\begin{array}{c}\text { Lecture duration should be of } 40 \\
\text { minutes }\end{array}$ & $43.4 \%(n=95)$ \\
\hline $\begin{array}{c}\text { Lecture duration should be of } 50 \\
\text { minutes }\end{array}$ & $8.7 \%(n=19)$ \\
\hline $\begin{array}{c}\text { Time allocated for SGD is } \\
\text { sufficient(90 minutes) }\end{array}$ & $93.6 \%(n=205)$ \\
\hline $\begin{array}{c}\text { Time allocated for SGD is } \\
\text { insufficient }\end{array}$ & $6.4 \%(n=14)$ \\
\hline Table-IV. Responses of students on time allocation for \\
a single lecture and SGD \\
\hline
\end{tabular}

\section{DISCUSSION}

In the recent past, comparison of learning in large group formats and small group discussions has been an important focus of educational research. ${ }^{11}$ There is a general agreement about better learning in small groups in terms of development of problem solving skills, critical thought process and better satisfaction of the students. ${ }^{12}$ Small group discussions help to develop interest, encourage curiosity and facilitate the environment of argument among the students. ${ }^{13}$ As a result, learning capabilities and performance of the students in examinations is improved. ${ }^{13}$

Integration is a main issue in medical undergraduate teaching methodology. It has been observed that learning in context of a clinical case scenario integrates student conceptual knowledge with understanding of the basic clinical sciences. ${ }^{14}$ The questions asked to the students during small group discussions help the students to understand the course of disease in integration with the basic clinical knowledge..$^{15}$

In our study we compared the student's preference responses between group discussions with lectures in undergraduate $3^{\text {rd }}$ and $4^{\text {th }}$ year MBBS students. In our study most of the students of CPMC $(70.3 \% n=154)$ were satisfied with the current pattern of teaching in subject of Pathology (Table-l). Students preferred small group discussions $(68.9 \% n=151)$ over comprehensive lectures $(31.1 \% \mathrm{n}=68)$ to learn pathology (TableII). These results are in close agreement with the study conducted by Rehana et al in Agha Khan University Karachi who concluded that students preferred small group learning over lectures as the favored methodology of learning in physiology subject. ${ }^{15}$ Medical undergraduate students showed a better post test score after learning via SGD as compared to didactic lectures in a study of University Medical and Dental College Faislabad. ${ }^{11}$ In another study conducted in Iran it was shown that students find SGD as a better learning and retaining medium in the Education of Basic Life Support and Advanced Cardiovascular Life Support for Medical Students. ${ }^{1}$ In a study 
conducted in Khwaja Safdar Medical College Sialkot on first year MBBS students majority of the participating students preferred small group discussions interactive lectures and problem based learning as teaching methodologies. ${ }^{16}$ The least preferred teaching methodology identified by medical students was didactic or comprehensive lecture. ${ }^{16}$ Novak and his coworkers found that pharmacy students learn best through problembased learning or small group discussions. ${ }^{17}$ This observation of ours is consistent with a study by Mukhtar and his coworkers who also showed that one way lecture was least preferred by the students in medical education. ${ }^{18}$ However, in a study conducted in Quaid-e-Azam Medical College Bahawalur, it was found that medical students considered small group discussions as a relatively less favored mode of learning as compared to comprehensive lectures. ${ }^{19}$

Students were also asked about the sufficient time allocation for the lectures and SGD along with most helpful method of teaching in SGD. The desired time limit for comprehensive lectures of pathology selected by majority of the participants was 30 minutes $(47.9 \% n=105)$, were as less positive responses were given to 40 minutes (43.4\% $\mathrm{n}=95)$ and 50 minutes $(8.7 \% \mathrm{n}=19)$ duration (Table-III). $93.6 \%(n=205)$ students thought that time allocated for small group discussions was sufficient (Table-III). A study conducted in Department of Obstetrics and Gynaecology of Fatima Jinnah Medical College Lahore showed that majority of the participants wanted the duration of one hour lectures to be halved. A very small percentage of participants could remain attentive during the lectures of one hour duration. ${ }^{20}$ In a study conducted in Fatima Memorial hospital Lahore, it was showed that according to most of the participants ideal duration of lectures was 30 min were as 60 minutes duration was preferred by only $2.3 \%$ of the participants. ${ }^{21}$ In our study, the most helpful way of teaching in SGDs stated by the students was discussions $(55.2 \% \mathrm{n}=121)$ followed by open book teaching $(38.4 \% \mathrm{n}=84)$ and slide presentations $(6.4 \% n=14)$ (Table-IV).
Small group discussions result in deeper and better understanding of the clinical knowledge and help to enhance problem solving skills in undergraduate medical students as compared to lectures. ${ }^{11}$ Student preference of small group discussions should compel the medical education departments in medical colleges to use this medium of learning as a preferred method of teaching. The importance of didactic lectures cannot be denied as they help in giving a broader picture of the topic under discussions, but the student learning can be enhanced by allocation more time to small group discussions than lectures.

\section{CONCLUSION}

Current study revealed that undergraduate medical students of Central Park Medical College preferred small group discussion as an effective teaching methodology relative to one way lecture. The current study indicate that according to $3^{\text {rd }}$ and $4^{\text {th }}$ year students of central park medical college, small group discussions lead to better learning as compared to LCF when compared in terms of preferred method of teaching. SGDs give a deeper insight of the topics and better interaction develops between the instructor and the student leading to an enhanced and improved learning. The response obtained from students during this study can be used to make new developments in teaching methodologies and produce an improved medical curriculum.

Copyright (C) 14 Nov, 2016.

\section{REFERENCES}

1. Hafezimoghadam $P$, Farahmand S, Farsi D, Zare M, Abbasi S.A Comparative Study of Lecture and Discussion Methods in education of Basic Life Support and Advanced Cardiovascular Life Support for medical students. Turkish Journal of Emergency Medicine. 2013; 13(2):59-63.

2. Rehman R, Khan R, Akhaai MA, Hassan F. Approach of freshly inducted medical students towards learning at Bahria University Medical \& Dental College. J Pak Med Assoc 2013; 63(3):320-6.

3. Papanna K, Kulkarni V, Tanvi D, Lakshmi V, Kriti L, Unnikrishnan B et al. Perceptions and preferences of medical students regarding teaching methods in a Medical College, Mangalore India. African Health Sciences. 2013; 13(3). 
4. Saleh A, Tawil N, Hadithi T. Didactic Lectures and Interactive Sessions in Small Groups: A Comparative Study among Undergraduate Students in Hawler College of Medicine. BJESBS. 2013; 3(2):144-153.

5. Davis AW. Successful small group teaching. Adv Psychiatr Treat. 1999;5:376-81

6. Nandi PL, Chan JNF, Chan CPK, Chan P, Chan L. Undergraduate medical education: comparison of problem-based learning and conventional teaching. HKMJ. 2000;6(3):301-6

7. Botelho MG, O'Donnell D. Assessment of the use of problem-orientated, small-group discussion for learning of a fixed prosthodontics, simulation laboratory course. Br Dent J 2001;191:630-6

8. Rehman R, Khan AN, Kamran A. Role of small group interactive sessions in two different curriculums based medical colleges. J Pak Med Assoc 2012; 62(9):920-3.

9. Chougule M, Patil P. Role of small group discussion in comparison to didactic lecture in improving selfdirected learning among first year medical students. Indian Journal of Basic and Applied Medical Research. 2015;1(5):501-505

10. Rehman R, Syed S, Iqbal A, Rehan R. Perception and performance of medical students in objective structured practical examination and viva voce. Pak J Physiol 2012; 8(2):33-6.

11. Hameed S, Khalid T, Aslam S, Ahmad M, Wattoo F. Small group discussion- Impact on students' test scores in an undergraduate pathology course. 2013;4(1).17-21

12. Jong Z, Nies A, Peters W, Vink S, Dekker W, Scherpbier A. Interactive seminars or small group tutorials in preclinical medical education: results of a randomized controlled trial. BMC Med Educ. 2010; 10:79.

13. Latif R. Impact of case-based lectures on students' performance in vascular physiology module. Adv Physiol Educ 2014; (38)3: 268-72.

14. Hudson JN, Buckley P. An evaluation of case-based teaching: evidence for continuing benefit and realization of aims. Adv Physiol Edu 2004;28:15-22

15. Rehman R. Clinically oriented teaching of Physiology through case based lecturing. Pak J Physiol 2014;10(12)

16. J Ayub Med Coll Abbottabad 2015;27(4) Bhalli M, Khan I, Sattar A. Learning style of medical students and its correlation with preferred teaching methodologies and academic achievement. J Ayub Med Coll Abbottabad 2015;27(4)

17. Novak S, Shah S, Wilson JP, Lawson KA, Salzman RD. Pharmacy students' learning styles before and after a problem-based learning experience. Am J Pharm Educ 2006; 70(4):74.

18. Mukhtar F, Hashmi N, Rauf MA, Anzar A, Butt $\mathrm{KI}$, Ahmed $M$, et al. Teaching methodologies; what is the students' perspective? Prof Med J 2012; 19(5):597603.

19. Qamar M, Ahmad A, Niaz K. Leraning through small group discussions versus didactic lectures. Pak Armed Forces Med J. 2015; 65(3):386-90

20. Najmi RS. Lecture as a mode of instruction in undergraduate medical education. J Pak Med Assoc.1999 Feb; 49(2):30-3.

21. Manzoor I, Mumtaz A, Habib M,Tariq S, Elahee M, Javaid I. Lectures in medical education: Students' views. J Ayub Med Coll Abbottabad 2011; 23(4):118-121.

\section{AUTHORSHIP AND CONTRIBUTION DECLARATION}

\begin{tabular}{|c|l|l|l|}
\hline Sr. \# & \multicolumn{1}{|c|}{ Author-s Full Name } & \multicolumn{1}{|c|}{$\begin{array}{c}\text { Contribution to the paper } \\
\text { Author=s Signature }\end{array}$} \\
\hline 1 & Dr. Hijab Batool & $\begin{array}{l}\text { Paper write up } \\
\text { Literature search }\end{array}$ \\
\hline 2 & Asim Mumtaz & $\begin{array}{l}\text { Theme, Data collection, } \\
\text { Results } \\
\text { Review and approval }\end{array}$ \\
\hline 3 & A.S Chughtai & \begin{tabular}{l} 
Revien \\
\hline
\end{tabular}
\end{tabular}

